\title{
On the Urban Environmental Pollution and Its Control in China
}

\author{
Ding Yuxian ${ }^{1, a}$, Jin Guohui ${ }^{1, b}$, Ding Yuxin ${ }^{1, c}$ \\ ${ }^{1}$ Inner Mongolia University of Science and Technology, Baotou, China, 014010 \\ ${ }^{2}$ Inner Mongolia University of Science and Technology, Baotou, China, 014010 \\ ${ }^{3}$ Hohhot Vocational School, Hohhot, China,010021 \\ amnb081223@126.com, dingyuxian@imust.cn, mnb1223@163.com
}

\begin{abstract}
Keywords: Urban Environment; Pollution; Control
Abstract:Urban environmental pollution and its control is one of the issues to be studied in the development of modern cities. It has strong pertinence and feasibility to guide the urban development in China that how the relevant theories will be used to analyze the current situation and causes of urban environmental pollution and to explore the countermeasures for environmental pollution control, thus realizing the coordination of urban environmental development and economic and social development and even achieving the sustainable development.
\end{abstract}

Urban environmental pollution and its control is one of issues to be solved in the development of modern cities. Subject to the rapid economic development, the urban development process, the urban population and the ecological environment pressure are all constantly increasing, resulting in the aggravation of urban-centered pollution, especially in the economically developed and populous large-and-medium-sized cities. It is those factors that constantly influence the development of urban economy and society. It is an important issue directly related to the sustainable development of city economy that how the relevant theories will be used to analyze the current situation and causes of urban environmental pollution and to propose the countermeasures for environmental pollution control, thus realizing the coordination of urban environmental and economic development. Therefore, from the perspective of the analysis of the current situation and causes of urban environmental pollution, this paper comprehensively describes the countermeasures for environmental pollution control to ensure the sustainable development of urban economy in China.

\section{Urban Environment}

Environment refers to the human-centered world of all materials around, namely the summation of all nature elements and social substances centered on human beings.

Urban environment refers to the urban economic, social and ecological system centered on human beings, with the characteristics of abandonment, chronicity, scalability, accumulation and intersectionality, and mobility.

\section{Urban Environmental Pollution}

The environmental pollution refers to the phenomenon harmful to the normal survival and development of human beings caused by the decline in the environment quality or landscape destruction due to human activities, which is a kind of harm resulting from the destruction of the ecological balance because the waste water waste gas, waste residue and other harmful substances from industrial production and human activities into the environment surpass the environmental purification ability in their concentrations or contents. At present, there are three most serious urban environmental pollutions:

One is the air pollution. Air pollution refers to that the concentration of pollutants discharged into the atmosphere surpasses its purification ability and becomes harmful, resulting in the deterioration of 
air quality and even affecting the ecological balance and human health. Since the reform and opening up, subject to the rapid development of industry, the consumption of fossil fuels and the emission of poisonous gases, smoke and dust are constantly increasing, especially in the developing countries. In addition, with the development of urban transportation, the emission of harmful gases from automobile exhaust to the atmosphere of the low altitude leads to more serious pollution. The UN statistics indicates that there are 50\% urban population living in the atmospheric environment out of limits, and about 1,000,000,000 people living in environment out of limits for smoke and dust. The air pollution in China is also quite serious, and the cities with atmospheric environment up to national primary standard account for less than $1 \%$ of the over 600 cities in China according to the relevant data.

Another is the water pollution. one of which is the domestic sewage. The domestic sewage mainly refers to a variety of water used in the daily life of urban residents. The compositions of domestic sewage vary with the cities, common in that the nitrogen, phosphorus and sulfur are higher in content, and it is easy to generate fetid substances in the role of anaerobic bacteria. In addition, there are a variety of trace metals, detergents and microorganisms in the domestic sewage. Each milliliter of domestic sewage may contain millions of bacteria, one of the main causes of natural dissemination diseases. The other is industrial wastewater, abundant, complex and toxic, which is the main pollution source of the water pollution. The statistics shows that there is about 5,000 tons of sewage (dominated by industrial wastewater) discharged into natural waters in the world every year, making $40 \%$ of rivers in the world yet polluted.

The water pollution is quite serious in China. According to the sampling survey, $82.3 \%$ of the 532 rivers (lakes) in China are contaminated, and some important rivers have even been seriously polluted. In the past 10 years, the annual growth rate of sewage is approximate to that of the gross output value of industry and agriculture.

The last one is garbage disaster. Garbage is the wastes in the process of human life and production, which is not only the "by-product" of human activities but also one public hazard in human society. The urban garbage may be classified into urban household garbage and industrial refuse.

Urban household garbage refers to the solid waste generated by city residents in their daily life. The high waste rate is a common fault in urban life caused by high production and high consumption. It is reported that the annual production of urban household garbage is about 200 million tons in the U.S.A, 70 million tons in Japan, and 2,000 million tons in the EEC countries with the increase rate of 3\%. The urban household garbage is also serious in China. It is shown by the aerial remote sensing data that there are nearly 5,000 garbage dumps of $50 \mathrm{~m} 3$ and countless small smoky mountains between the Third Ring Road and the Fourth Ring Road in Beijing, forming the "Great Wall of Garbage" in China. According to the relevant statistics, in 2000, the urban household garbage in China amounted to 150 million tons, leading $2 / 3$ cities to be surrounded by garbage.

Industrial refuse refers to the industrial solid waste discharged by the industrial and mining enterprises in the production process, such as the waste residues. Compared with household garbage, the industrial refuse is larger in quantity and more intense in harm. At present, the world's annual generation of industrial refuse is about 2 billion tons, which is already 0.62 billion tons in China in 1994 with the average deposit volume per square kilometer is 64.5 tons. The accumulated industrial refuse amounted to 6.46 billion tons over the years, 5.38 tons per capita, covering an area of 55,700 ha.

The major causes of those pollutions are as follows: due to the lack of knowledge, attention paid to the urban environment is not enough; the unreasonable industry structure leads to the backward economic growth mode; the environmental governance is ineffective and the investment in environmental protection is insufficient; the weak environmental awareness of the public makes the governance by law ineffective. The reasons above jointly resulted in the severe imbalance of economic and social ecological system with the urban natural environment in China and even hindered the implementation of the strategy of sustainable development, which shall be highly valued by the whole society. In particular, the comprehensive management of urban environment shall be enhanced, so as to ensure the healthy and sustainable development of the urban economy and society in China. 


\section{Countermeasures of Urban Environmental Pollution Control}

China and the Communist Party of China have paid great attention to the increasingly acute contradictions between the urban environment and the economic and social development as well as the serious consequences incurred hereby. The environmental protection regulators at all levels have been set up successively, with the Environmental Protection Law of the PRC and the relevant regulations and policies introduced, thus effectively protecting the urban environment in China. The existing countermeasures of urban environmental pollution control in China are mainly as follows:

\section{Strengthening the urban planning for the management of urban environment}

At present, the natural ecological level may be included in the agenda of governments all levels, not only as an important tool to judge whether the sustainable development is possible in a city, but also as an important factor to judge whether a city will open wider to the outside world, attract foreign investment and accelerate the development, and improve people's lives. The scientific urban planning of advancement will be then formulated to coordinate the urban environment and the economic and social development. Equal importance shall be paid to the following matters when preparing the urban planning: development and environment protection; intensive saving and development; planning formulation and adjustment; local ecological coordination and regional division. At the same time, attention shall be paid to the regional planning and urban system planning from the perspective of regional economic integration, so as to realize the reasonable regional division of work and urban division of duties and thus form the regional urban network system with a clear division of labor and in a mutual cooperation relationship. Make overall arrangements based on the regional conditions between cities and between the city and the country, thus giving full play to their advantages and avoiding the intensified pollution caused by the competition for resources and energy and the redundant construction.

\section{Implementing the "Green Revolution" to improve the urban environment}

Under the rapid development of modernization, China shall learn from the industrialization and modernization experiences of other countries; completely change the mode of "pollution first and treatment later"; use the manpower, material and financial resources for air purification and the treatment of water and solid waste to prevent and remedy the pollution; realize the low pollution and high efficiency from the source; and implement the "Green Revolution" with modern science and technology.

\section{Regulating the urban ecology to purify the urban environment}

Forest is the natural plant for air purification. The analog computation by America Environmental Protection Bureau shows that 1 hectares of forest may not only absorb 748 tons of SO2 and 0.38 tons of NOX every year, but also filter and absorb the smoke, dust and metal ions such as mercury and lead in the air as well as the radioactive substances. Therefore, it is encouraged to plant trees and flowers in the city.

\section{Reforming the investment system to increase the investment in environmental protection facilities}

It is the basis of the ecological system in virtuous cycle with self-purification ability to perfect the supporting construction of urban environmental infrastructure, thus accelerating the construction pace of infrastructures such as city roads, water supply and protection, solid waste treatment, sewage closure, sewage treatment and urban green space. In face of the serious urban environmental pollution and various infrastructure arrears, China shall reform the investment system of urban environmental protection to increase the investment in environmental protection facilities.

\section{Strengthening the public education to raise the public awareness of environment protection}

Vigorously carry out environmental education activities to help the public establish the awareness of modern city; carry out education activities widely and deeply in the public to improve the environmental awareness; carry out competition games to beautify the environment in various forms and of various series, so as to put the environmental awareness into the practice. 


\section{Implementation of "pollution control by law" to comprehensively manage the urban environment}

Learning from Japan and U.S.A, China shall formulate the corresponding laws and regulations base on the Environmental Protection Law of the PRC to strictly control the discharge of pollutants, especially the effective systems for pollutant emission control in the environmental protection in China, thus establishing the synchronized management mechanism of environmental control and protection with the economic social development.

\section{Summary}

Through the comprehensive management of the pollution issues above, the urban system in China will be restored, and the obvious contradictions between urban environment and sustainable economic and social development will be coordinated. In addition, the urban environment and the economic and social ecological systems are becoming unified, thus realizing the sustainable development of economy and society eventually.

\section{References}

[1] Liu Tianqi, et al. Introduction to Environmental Protection. Higher Education Press, 1982.

[2] Xiong Guoping. Strategy of Sustainable Development and City Planning, Urban Development Research. 1998(4).

[3] Wang Guojian. Principle of Ecology and Green Urban Design, Journal of Architecture. 1997(6). 